\title{
Política y Televisión: Las Perversiones de la democracia
}

\author{
Dr. Antonio Laguna Platero \\ Universidad Cardenal Herrera-CEU San Pablo Valencia
}

\section{RESUMEN}

La esencia del sistema democrático es la participación política, la expresión de lo que la gente desea. Pero este deber de participación descansa sobre otro complementario: el derecho a la información.

La representación política y la información política del ciudadano están sustentandos por dos intermediarios: en primer lugar, por los partidos políticos, que 'deben ser democráticos' de acuerdo a la Constitución; y en segundo lugar, por los medios de comunicación, que deben estar bajo control parlamentario en caso de que sean públicos.

Pero nosotros debemos advertir que no se realiza ninguna recomendación al respecto. La relación entre medios de comunicación y partidos políticos, teniendo en cuenta que hablamos de una necesidad recíproca, es también interactiva, lo que puede causar diferentes efectos de diversa índole, algunos tan difíciles y profundos que pueden ser considerados como factores determinantes en valores políticos y democráticos de nuestra sociedad.

\section{ABSTRACT}

The essence of the democratic system is political participation, the expression of people's will. But this participation duty rest on another complementary one: the right to information.

Both political representation and the citizen's political information are hold by two intermediaries: firstly, the political parties, which "must be democratic" accordant to the Constitution; and secondly, the media, which must be under the parliamentary control in the case they are public ones. But we should point out that neither recommendation is carried out. The relationship between media and political parties, taking into account that it's a reciprocal necessity, is also an interactive one, which can cause a sour of effects so varied, difficult and profound that, in many cases, they are considered as determining factors in the political and democratic values culture of our present society.

Palabras claves: Democracia/Participación política/Televisión/Partidos Políticos/Constitución Española/Efectos de la comunicación.

Key words: Democracy/Political participation/Television/Political parties/Spanish constitution/ Communication effects. 


\section{Por la televisión a la política}

o hay política sin medios" -afirma Raúl Trejo-, pero entre una y otros
la relación parece cada vez más desigual ${ }^{1}$. La política se define como
democrática en la letra de la Constitución española, mientras que los
medios de comunicación se resuelven privados por el espíritu redivivo de A. Smith. La política democrática se basa en principios como la representación, la participación, la transparencia y, sobre todo, la información, principios todos ellos ligados directa o indirectamente al mundo de la comunicación. El funcionamiento democrático, por tanto, está estrechamente unido al modo y forma en que los intermediaros mediáticos lleven a los hogares de los ciudadanos el mundo de la política.

Sabemos que de esos intermediarios sobresale con distancia uno: la televisión. De acuerdo con el barómetro del CIS de julio de 2000, (Estudio N ${ }^{\circ}$. 2.396), la radiografía realizada sobre el consumo que los españoles hacen de este medio, ofrece los siguientes parámetros:

- El 79\% de los españoles ve todos o casi todos los días la televisión, frente al $45,5 \%$ que afirma escuchar la radio diariamente y el 26,3 que reconoce leer todos, o casi todos, los días la prensa.

- Que de ese porcentaje, la mayor parte (un 35,3\%), se pasa entre 1 y 2 horas a partir de las 9 de la noche, mientras que los que escuchan la radio en esa misma cantidad de entre 1 y 2 horas son el $29,6 \%$ y en horario de mañana.

- El $67 \%$ de les televidentes reconoce ver todos los días algún telediario. En el caso de los informativos radiofónicos, el 48,4\% de los encuestados afirma oírlos todos los días.

- Además, 1 de cada 2 televidentes reconoce que los telediarios son el programa que más les gusta. También los radioyentes colocan a los informativos como su programa preferido $(45,6)$ por delante de los musicales $(42,4)$.

- Sin embargo, ante la pregunta de ¿Qué confianza le merecen a Ud. las noticias que dan las distintas cadenas de televisión? El 58,4\% dice que bastante, el 21,2 que poca y el 13,5 que mucha. En el caso de la radio, la pregunta obtuvo una respuesta similar: el 58,8 que bastante, el 13,1 que poca y el 18,5 que bastante.

Llegamos así al fondo de la cuestión. Si reconocemos que la mayor parte de nuestra población ve e identifica el mundo de la política a través de los telediarios, empezaremos a pensar que en el interior del televisor se esconde algo más que un

1 TREJO DELABRE, Raúl: “La política por otros medios”, en Razón y Palabra, No 12, 1998-99. 
medio de transmisión de señales. Empezaremos a intuir que el futuro de la política y de los políticos estará absolutamente condicionado por la imagen que transmita la pantalla al resto de los ciudadanos. Empezaremos a entender que algo nuevo y absolutamente desconocido para los "padres de la Constitución", está afectando al funcionamiento democrático y a sus actores principales (partidos, líderes, candidatos, gobernantes, votaciones...)

El tema es tanto o más importante si cabe, cuando una buena parte de la sociedad identifica la televisión con distracción, entretenimiento o evasión y no como un medio clave de comunicación política. Por eso lo convierten en parte temporal de su existencia, en eje central de su vida familiar, en la ventana indiscreta que permite soportar la convalecencia de una pierna rota que, al igual que en la película de Hitchcock, no se recupera nunca.

Y el tema es tanto o más paradójico si cabe, cuando reconocemos que el medio socialmente más implantado y consumido en nuestro país es, a su vez, el más desconocido. ¿Qué sabemos sobre su funcionamiento, sobre las peculiaridades de su lenguaje, las limitaciones de su formato, las hipotecas de su modelo económico, los efectos de sus mensajes y la influencia que ejerce en las personas? ¿Qué sabemos sobre los efectos políticos?

\section{Qué papel juegan los medios de comunicación en nuestra democracia}

La democracia española, como cualquier otro sistema basado en el mismo orden de valores, descansa en un pilar fundamental: la participación política, la manifestación de la soberanía popular. De forma regular, los ciudadanos son apelados por las instituciones representativas a manifestar mediante el voto su opinión y su deseo de gobierno. De esta participación electoral saldrá una representación parlamentaria que ejercerá el poder legislativo con la misión de hacer las leyes, elegir y controlar al ejecutivo, así como determinar las competencias y garantizar la independencia del poder judicial.

Pero este derecho de participación descansa en otro complementario: el derecho a la información. Sin un conocimiento preciso de las opciones que están en juego, sin una información rigurosa de las ofertas electorales que concurren en la pugna electoral y, sobre todo, sin una transparencia comunicativa de las acciones de gobierno, el resultado desvirtúa la razón de ser del sistemá Lo advertían

2 Abraham Lincoln formuló esté concepto de la manera más sucinta posible cuando dijo: "Que el pueblo conozca los hechos, y el país estará a salvo". Thomas Jefferson abrigaba sentimientos tan fuertes acerca del principio de la libre expresión que manifestó: "Si yo tuviera que decidir entre un gobierno sin prensa y una prensa sin gobierno, no vacilaría un instante en preferir lo segundo". KRIMSKY, G. A. : "La función de los medios de información en una democracia", en Temas de Democracia, Publicación Electrónica de USIS, Vol. 2, No. 1, febrero, 1997. DEL REY MORATO, Javier: La comunicación política. Eudema Universidad, Madrid, 1989, p. 47. DEL REY MORATO, Javier:Democracia y Posmodernidad. Teoría general de la información. Editorial Complutense, Madrid, 1996, pp. 54-55. 
de forma interesada los teóricos de lo que fue el liberalismo doctrinario, cuando en el siglo XIX justificaban por qué el derecho del voto tan sólo podía ser para los ciudadanos plenamente conscientes, esto es, aquellos que tenían riqueza y cultura ${ }^{3}$.

La democracia, por tanto, fue durante siglo y medio en España una utopía impracticable porque los posibles electores, al ser pobres o incultos, nunca podrían conocer correctamente la opción política que les convenía. Así opinaba, por ejemplo, un Cánovas del Castillo cuando en 1890 se debatió en las Cortes la aprobación del sufragio universal masculino para los mayores de 25 años. Y así opinaban en los inicios de la transición quienes se negaban a reconocer que el franquismo había quedado bajo una losa en el Valle de los Caídos.

Por suerte, las duras e intensas luchas que se dieron en buena parte de nuestra Historia contemporánea por conquistar un sistema democrático, dieron finalmente sus frutos en 1978 con la Constitución que regula y certifica el sistema político. En su articulado se recogen los principios fundamentales de la información y la participación: "el derecho a comunicar o recibir libremente información veraz por cualquier medio de difusión" (art. 20. d); y "el derecho a participar en los asuntos públicos, directamente o por medio de representantes, libremente elegidos en elecciones periódicas por sufragio universal" (art. 23.1). Ambos quedarían complementados con un artículo anterior que reconoce que "Los partidos políticos expresan el pluralismo político, concurren a la formación y manifestación de la voluntad popular y son instrumento fundamental para la participación política" (art. 6). Como se descubre, se trata de un artículo que atribuye un papel capital al partido político al convertirlo en un puente entre la sociedad, un mediador de conflictos, un espacio público para el debate social... En definitiva, en un instrumento de participación para la toma de decisiones. Sin embargo, no olvidemos el deseo que manifiesta este artículo sexto de nuestra Constitución en su parte final: "Su estructura interna y funcionamiento deberán ser democráticos"4.

3 MUÑOZ ALONSO, Alejandro: "Génesis y aparición del concepto de opinión pública”, en Opinión Pública y Comunicación Política. Eudema Universidad, Madrid, 1990, p. 56

4 Esta distancia entre lo que debería ser y lo que realmente es, también resulta notoria en el caso de los partidos políticos. Pues, más allá de su función representativa, está su funcionamiento orgánico, su estructura de poder y la pléyade de militantes que aspiran a formar parte de la clase política. De acuerdo con el diagnóstico que el profesor Ignacio Sotelo realizaba en la revista Política Exterior ( $\mathrm{n}^{\circ}$ 17, 1995), dos son las condiciones que deben cumplir los afiliados de un partido que aspiren a un cargo público: $1^{\mathrm{a}}$. unirse a un clan, al que ha de ofrecer como todo bagaje una lealtad inquebrantable; $2^{\mathrm{a}}$. obediencia ciega al jefe. En consecuencia, si estos son los principios de selección, el resultado será que los elegidos, intelectual y sobre todo moralmente, estarán muy lejos de dar los mínimos exigibles en un sistema democrático, amén de convertir al partido en una organización de personas interesadas en vivir de la política a cualquier precio. El maquiavelismo pasará a ser la principal escuela y la intriga un principio de actuación. 
En resumen, tanto la representación como la información política de los ciudadanos -pilares básicos de nuestro sistema democrático- están en manos de sendos intermediarios: en el primer caso, los partidos políticos, de los que la Constitución -acabamos de ver- dice que "deberán ser democráticos"; y en el segundo, los medios de comunicación, de los que la Constitución señala, cuando sean de titularidad pública, que quedarán bajo el control parlamentario.

\section{Partidos y medios: Una relación de interés}

Estamos detectando la gran paradoja de nuestro sistema democrático, al descubrir que entre el cielo y la tierra, entre los ciudadanos y el poder se sitúan dos instituciones - partidos y medios- que tienen la responsabilidad de representarnos e informarnos, esto es, de hacer efectiva la realidad de un sistema democrático definido en la letra de nuestra Constitución. Por esta razón, ambos forman una relación simbiótica de honda raíz histórica que se remonta a los inicios del sistema liberal, allá por el 1808. En la historia de los partidos políticos, desde los liberales del siglo XIX hasta los democráticos de hoy día, la presencia del órgano o portavoz periodístico ha sido una constante reiterada. Entre otros motivos, por algunos que le resultan vitales: el partido necesita de los medios de comunicación para hacer visible sus aspiraciones, para propagar sus críticas y, finalmente, para ganar seguidores activos -militantes- o pasivos -votantes-. Incluso necesitan una estrecha relación con los profesionales del medio para conseguir la mejor selección posible de los mensajes informativos que transmitan. A ello hay que añadir la creación, por buena parte de todas las Instituciones, de gabinetes de comunicación con el objeto de convertir en noticia las actividades y declaraciones propagandísticas que realiza el político de turno, a partir de la constatación de que la propaganda, si se viste de noticia en un telediario, es siempre mucho más efectiva.

En cuanto al medio de comunicación, en la medida en que va consolidándose una estructura empresarial que hace del beneficio su máxima de actuación, la vinculación directa con los partidos desaparece. Sin embargo, la separación es más formal que real. Porque, entre otras cosas, el medio de comunicación necesita de la política para llenar buena parte de sus espacios; necesita de la publicidad que generan las instituciones públicas para conseguir un ingreso extra importante; y necesita de los políticos para seguir cultivando esferas de influencia que tarde o temprano se traducen en resultados concretos. Además, en los medios audiovisuales de titularidad pública la vinculación con el partido en el gobierno es tan estrecha que el más simple de los análisis de mensajes pone de manifiesto la enorme diferencia de trato que dispensan a quien gobierna y a quien oposita. El caso de la televisión autonómica valenciana, Canal 9, los propios trabajadores del Comité de Redacción han elaborado sucesivas memorias anuales que demuestran con profusión de datos incontestables y contundentes la estrecha vinculación que 
ha existido entre la televisión pública de los valencianos y los intereses concretos del Partido Popular y Eduardo Zaplana 5 .

La relación entre medios y partidos, en la medida en que es de necesidad recíproca, también es de afección mutua, llegando a provocar efectos tan variados, complejos y profundos que, en muchos casos, se les considera determinantes de la cultura política y de valores democráticos de la sociedad actual. Esto es, responsables sociales. Sin embargo, aquí sí que se manifiesta una importante diferencia: mientras los representantes políticos son responsables ante su electorado y ante su partido, lo que puede provocar su remoción al cabo de un tiempo, los medios de comunicación privados o públicos son irresponsables, queremos decir, no contraen más responsabilidad que la de servir a los objetivos diseñados en un consejo de administración.

Paradójico, verdad: los medios llamados de masas, dirigidos a millones de telespectadores, capaces de iluminar una realidad y ocultar otra, de fomentar la conciencia o aletargarla, resulta que dependen de unos pocos que los poseen o gestionan. El único tribunal donde sólo rinden cuentas, al menos los medios privados, es el mercado. Más paradójico aún: los medios de comunicación son considerados servicios públicos por la función social que desempeñan de aportar a los ciudadanos la sabia democrática de la información. Y, sin embargo, su responsabilidad es como la de cualquier otra empresa, estrictamente económica.

\section{La lógica televisiva: El nuevo despotismo ilustrado}

Los medios de comunicación privados $-\mathrm{y}$, en ocasiones hasta los públicosse convierten en sujetos contradictorios entre sus principios teóricos de actuación y sus principios empresariales, o lo que podríamos llamar entre su razón de ser y su razón social, renovando la máxima que identificara al despotismo ilustrado del siglo XVIII de todo para el pueblo, por el pueblo, pero sin el pueblo. Queremos decir, entre su principio de toda la información para el público y por el público, pero sin que el público se entere de lo que es la empresa ${ }^{6}$, de cómo trata a sus

5 En relación con los informativos, en la III Memoria elaborada por el Comité de Redacción de Canal 9, para los meses de mayo de 1998 al mismo mes de 1999, se afirmaba: «Obviant l'obligat compliment de la llei, menyspreant el dret dels ciutadans a rebre una informació lliure i veraç i ignorant la llibertat d'expressió dels professionals, els directius del departament d'Informatius de Canal 9 (Pau Pérez Rico i els seus més estrets col·laboradors Menchu Illán, Jesús Martínez, Josep Magraner, Lluís Motes, Rodolfo Ferrer i Rafael Medina) són responsables d'una continuada manipulació i censura informativa que pretén beneficiar els interessos polítics d'Eduardo Zaplana i el Partit Popular. Tant la Llei de Creació com l’Estatut de Redacció consagren els principis de pluralisme i imparcialitat en la informació però els noticiaris de Canal 9 fan just el contrari: són partidistes, parcials i, sempre, a favor del PP. Qualsevol notícia que puga perjudicar els interessos del Partit Popular s'amaga. Tot allò que pot resultar beneficiós, s'exagera i sobredimensiona".

6 Bien es cierto que esta opacidad queda rota gracias a trabajos como los del profesor REIG, Ramón: Medios de comunicación y poder en España. Prensa, radio, televisión y mundo editorial. Paidós Comunicación, Barcelona, 1998. También el libro de FERNÁNDEZ, Isabel y SANTANA, FernandaEstado y medios de comunicación en la España democrática. Alianza Editorial, Madrid, 2000. 
periodistas, de qué criterios determinan su forma de trabajo, su selección de noticias o cómo la publicidad puede condicionar los contenidos.

El medio de comunicación, amparado por el principio constitucional del derecho a la información o el derecho del público a conocer la verdad, podrá y deberá investigar cualquier indicio de noticia que llegue a sus pituitarias; podrá y hasta utilizará fuentes de información que no desvelará -dirá aquello de "fuentes bien informadas" o "nota de la redacción"- para denunciar lo oculto del mundo que le rodea. Pero ese mismo medio no dirá por qué investiga ese asunto y no otro, por qué denuncia ese tema y no otros. Argüirá que su guía es seleccionar todo lo que pueda ser de interés social, todo lo que tenga una determinada relevancia social. Y callará que la escala de la relevancia no la marca el público sino, justamente, los propios medios de comunicación. Fue la investigadora alemana Elisabeth Noelle Neumann la que demostró en los años sesenta cómo los temas que seleccionaban los medios -el concepto de Agenda-Setting que formularían Mc Combs y Shaw (1972)- pasaban a convertirse en los temas que marcaban el debate público y no al revés?.

La importancia de los medios en la conformación de la opinión pública no sólo les proporciona una gran capacidad de influencia, sino también una enorme responsabilidad social. $\mathrm{Y}$, sin embargo, las dos características que definen el modelo público de televisión en España, a juicio de Díaz Nosty, son: en primer lugar, la vinculación de la información a los intereses del gobierno; y, en segundo, "la supeditación de los valores culturales y cívicos de referencia del Estado de derecho a meros criterios de explotación mercantil"».

Las polémicas que se originan sobre estos dos aspectos, corroboran ambos perfiles. En el primer caso, el debate se origina siempre a raíz del tratamiento a favor que la televisión pública realiza del gobierno, lo que reabre una y otra vez la necesidad de redefinir el modelo televisivo, sobre todo en los mecanismos de dirección y control. La televisión española, a diferencia de la europea, carece de cualquier autoridad de control de sus contenidos, un Consejo del Audiovisual, tal y como se planteó en 1998. Se trata de una asignatura más que ha quedado pendiente de nuestra transición democrática. El modelo de televisión estatal al servicio de una ideología que se heredó del franquismo, fue aprovechado en beneficio propio por Adolfo Suárez ${ }^{9}$. Lo mismo hizo Felipe González con notables resultados (referéndum de la OTAN). Por el camino fueron apareciendo las televisiones autonómicas que no hicieron sino imitar el ejemplo, haciendo recaer en

7 WOLF, Mauro: Los efectos sociales de los media. Paidós, Barcelona, 1994, pp. 59-75

8 DIAZ NOSTY, Bernardo: Informe anual de la comunicación, 1999-2000. Estado y tendencias de los medios en España. Grupo Zeta, Barcelona, 2000, p. 206.

9 PALACIO, Manuel: Historia de la televisión en España. Gedisa, Barcelona, 2001, p. 106-108. Sobre el papel de la televisión en las primeras elecciones democráticas, CONTRERAS, José Miguel: Vida política y televisión. Espasa-Calpe, Madrid, 1990, p. 65. 
un Consejo de Administración dominado por el partido gobernante la dirección del medio. Con el gobierno Aznar, el control se ha elevado a una nueva dimensión. Ya no se controlan sólo los contenidos de las televisiones públicas gobernadas por el partido. También se interviene en las privadas a través de terceros -testaferros podríamos decir- que dan el nombre pero que no ponen el dinero. Esta obsesión de cada gobierno por dirigir los medios públicos "encuentra sus razones en la nula penetración de la prensa de partido y en la escasa presencia de los medios escritos en las clases populares" 10 .

En el segundo caso, la televisión dominante en España se rige por una lógica económica que le lleva a subordinar toda su estrategia en función de las audiencias. De tal manera que los contenidos no se medirán por razón de su interés cultural, social o político, (función social de servicio público) sino por la cantidad de espectadores que es capaz de congregar para venderles publicidad (función mercantil tradicional). El efecto más notorio fue cuando hace apenas un lustro se incorporó la publicidad a los telediarios, lo que ha provocado un curioso contraste de noticias: por un lado, los asuntos políticos, complementados con varias catástrofes, notas sociales y deportivas; y en medio de todo, los anuncios de una felicidad que se logrará con tan sólo comprar y consumir ${ }^{11}$. Las televisiones en general y más allá de sus hipotecas políticas, apuntan todas sus actuaciones hacia la cuenta de resultados, esto es, la venta de espacios televisivos a quien esté dispuesto a pagarlos. Y es aquí donde de forma más nítida se observa que la información se presenta más como un acto de consumo de mensajes que como la participación en un proceso colectivo de debate social.

Lo que diferencia la televisión pública de la privada es básicamente su finalidad, por encima de todo política, lo que nos permitiría entender las enormes deudas que arrastran. Sin embargo, su modelo operativo es también comercial: venta de espacios al mejor postor. Aparentemente puede parecer contradictorio. Pero tiene su explicación: se trata de recurrir a todas las estrategias de la televisión comercial para conseguir ganar audiencia, esto es, influencia. Y cuando ya se tiene un buen auditorio, presentar la realidad de acuerdo con el esquema previo establecido de favorecer a los míos y perjudicar a los otros.

Pero más allá de este punto de vista finalista, de conseguir cuotas de pantalla elevadas que atraigan publicidad y permitan mayores ámbitos de influencia social, tanto las televisiones públicas como las privadas comulgan y practican la misma religión, la del mercado. Un principio común de actuación que explicaría por qué ninguna televisión estuviera cumpliendo la directiva comunitaria de

10 JEREZ, A., SAMPEDRO, V. y BAER, A. : «Medios de comunicación, consumo informativo y actitudes políticas en España”, en Opiniones y Actitudes, No 32, CIS, Madrid, 2000, p. 47.

11 RICHERI, Giuseppe: La transición de la televisión. Análisis del audiovisual como empresa de comunicación. Bosch, Barcelona, 1994, p. 33-38. 
Televisión sin Fronteras, aprobada en 1999, y que señala expresamente la limitación de la publicidad a un máximo de 17 minutos por hora. En este sentido, recordemos que la cantidad de publicidad emitida por la televisión en España en 1998 fue de 3.671 spots al día, lo que constituía una cantidad de 1.261 minutos al día, esto es, 21 horas entre todas las televisiones.

Domina y gana en todas nuestras televisiones el modelo comercial, cuyo principio de actuación fue definido hace algunas décadas por uno de sus principales protagonistas, el magnate Axel Springer con la siguiente máxima: "lo que hace pensar aburre y no vende". Este principio, en una sociedad donde la oferta genera su propia demanda, acaba retroalimentándose. Es decir, en la medida que se oferten menos contenidos que estimulen la reflexión y más se potencie el divertimento evasivo, menos demanda habrá de contenidos políticos. Es más, la inexistencia de alternativas provoca, a su vez, la homogeneización de contenidos, sobre todo en aquellas franjas horarias de mayor audiencia. Se trata, sencillamente, de imitar el producto de éxito de la cadena rival, mediante lo que se ha identificado como "contraprogramación" y que también está prohibida por la normativa citada anteriormente de Televisión sin Fronteras.

En este modelo comercial, la filosofía acaba siendo también disciplina de trabajo. Queremos decir, que de la misma forma que la maqueta del periódico la decide el anuncio, en la televisión el tiempo informativo será subsidiario del comercial lo que impedirá que una noticia de política cotidiana tenga una explicación prolija. Además, tanto en la selección como en el tratamiento, la complejidad será sustituida por la simpleza del razonamiento y la trivialidad del suceso. Todo ello en aras a captar la mayor atención posible. Entramos así en la veracidad del medio, su fuerza mediadora, y las posibilidades de construir un mundo virtual.

\section{Una realidad adaptada a la televisión: La política espectáculo}

Es evidente que los contenidos de nuestras televisiones no sólo quedan condicionados por su lógica económica o política de funcionamiento. También les afecta de forma importante la complejidad tecnológica del medio y la especificidad de sus lenguajes.

El proceso de fabricación y emisión de imágenes se ha presentado socialmente con un reduccionismo muy alejado de la verdad. La afirmación de que la cámara es el ojo objetivo, aunque indiscreto, y que por lo tanto los medios son "ventanas al mundo", se une a determinadas creencias igualmente falsas sobre que "una imagen vale más que mil palabras o "que así son las cosas y así se las hemos contado" (Buruaga dixit). De tal manera que la televisión supedita la actualidad a la fuerza de las imágenes, relegando las palabras y los textos a un plano secundario y limitado. La prioridad de los televidentes no es tanto comprender el alcance de un acontecimiento, sino simplemente verlo: "De este modo se establece, poco a 
poco, la engañosa ilusión de que ver es comprender"12, de que "una imagen vale más que mil palabras" o de que "ver para creer" Y, sin embargo, nada más alejado de la realidad.

Los medios en general y la televisión en particular, seleccionan la realidad de la que van a dar cuenta en función del grado de atención que despertará y del impacto que tendrá entre público y anunciantes. Además, la selección de hechos tampoco responderá a una descripción que podríamos llamar lineal -recorrido continuo de la cámara, pongamos por caso-, sino que se adaptará a la finalidad dramatizadora e impactante del medio. "En la medida en que la estrategia se basa en seducir a partir de la imagen y no del argumento, la forma pasa a ser el fondo: se magnifica el personaje, se simplifican las ideas y el debate. Los mensajes van siendo reducidos a frases de impacto hasta convertirse en consignas. El spot televisivo exige grandes verdades y no verdades matizadas"13. La realidad, por tanto, se tiene que adaptar al interés del empresario, a la forma de trabajar del periodista y al lenguaje propio de cada medio. Es "el yo pondré la guerra" de W. R. Hearst.

La clave informativa del medio audiovisual -y en menor escala del impresoes la interpretación. Quiere decir que la realidad no se selecciona porque sí, sino en función del grado de atención que alguien interpreta que despertará entre público y anunciantes. Además, la selección de hechos tampoco responderá a una descripción que podríamos llamar lineal -recorrido continuo de la cámara, pongamos por caso-, sino que se adaptará a la finalidad dramatizadora e impactante del medio.

En la televisión, el tiempo de la información más valioso es el del tiempo real. Esta premisa de trabajo ha calado tan profundamente en la sociedad que ha acabado por provocar un nuevo concepto de lo que es la información: simple y llanamente, se entiende que informar es mostrar la historia en marcha o, más concretamente, hacernos asistir en directo al acontecimiento. Y la veracidad de esta información ya no reside en la calidad del trabajo periodístico, sino en la repetición que tenga en el resto de medios.

Este modo de informar de la televisión, -"que muestra sin comprender o explicar”, que diría I. Ramonet-, también se ha extendido en alguna medida al

12 "El receptor ve directamente, por tanto, participa en el acontecimiento. Se autoinforma. Si se equivoca, él es el responsable. El sistema culpabiliza al receptor, que ya no puede hablar de mentiras, porque se ha informado solo. De este modo, el nuevo sistema acredita la ecuación «ver es comprender». Pero la racionalidad moderna, con la Ilustración, se hace contra esa ecuación. Ver no es comprender. No se comprende más que con la razón. No se comprende con los ojos o con los sentidos. Con los sentidos uno se equivoca. Es la razón, el cerebro, es el razonamiento, es la inteligencia, lo que nos permite comprender. El sistema actual conduce inevitablemente o bien a la irracionalidad, o bien al error". RAMONET, Ignacio:

La tiranía de la comunicación. Editorial Debate, S.A., Madrid, 1998, (2 edi.), p. 50.

13 JEREZ, A., SAMPEDRO, V. y BAER, A. (2000): op. cit., , p. 49. 
mundo de la prensa. No resulta difícil encontrar diarios que, en su portada, parecen mosaicos de imágenes provocativas, y en su interior un sumario de grandes titulares con artículos breves. Es decir, la prensa par ver y no tanto para leer, también constituye ya una realidad. En cualquier caso, el resultado de este tipo de información es una serie de estímulos que reducen el acontecimiento a su expresión visual, emotiva e impactante, imposibilitando cualquier razonamiento sobre las causas o los efectos del acontecimiento.

El proceso no hace sino crecer. El telediario de hoy, frente al de ayer, sigue incrementando el valor imagen frente al argumental, textual o explicativo. Las declaraciones de los actores políticos se limitan a frases aparentes; se incrementa el ritmo visual, imitando de esta forma el ritmo expositivo del mundo de la publicidad; la narración se hace dependiente de (o se adapta a) las imágenes disponibles; se radicaliza la tendencia a la espectacularidad en el tratamiento de la noticia, convirtiendo el dramatismo y el énfasis en ingredientes habituales de la noticia.

Y todo esto por una razón básica: en televisión, el tiempo es oro. Esta manida afirmación no hace sino constatar la lógica mercantil del tiempo televisivo y demostrar cómo el punto final de toda programación -sea del tipo que sea- no es otro que la venta a las audiencias de publicidad. El sueño de cualquier propietario de televisión sería que su cadena fuese seguida por millones de espectadores, durante muchas horas, y que emitiese sólo anuncios de 30 segundos de duración como máximo. Por eso el ritmo de la información es vertiginoso, ya sea en una emisora privada o pública.

No ocurre lo mismo - al menos por ahora- con la información impresa. La prensa suele dedicar más espacio y tiempo a la información, al tiempo que su formato y lenguaje posibilitan la contemplación reiterada del texto que leemos, la reflexión acerca de su contenido y, en ocasiones, hasta la motivación para ampliar datos sobre el tema.

La comparación de la misma información en los distintos medios arroja una clara diferencia. Pongamos por caso el debate sobre el estado de la nación celebrado en el mes de junio del 2001. De acuerdo con el estudio del CIS, $\left(\mathrm{n}^{\circ}\right.$ 2418), el 74,4\% de los españoles tenía conocimiento de la celebración el debate; el $39,9 \%$ de los españoles que siguieron en directo la sesión, lo hicieron por televisión, el 4,6\% por la radio y el 9,8\% por los dos medios alternándolos. Sin embargo, el 45,3\% no siguió ni se interesó por el debate. Pero más allá del directo, el 28,5\% tuvo información posterior de lo que ocurrió gracias a la televisión, el 10,6 por la radio y el $13,3 \%$ por la prensa, mientras que el $60,5 \%$ no tuvo ninguna noticia o no le interesó el tema. A tenor de estos datos, los resultados son claros:

1. La política, concretada en el debate estrella de la legislatura, tiene un interés relativo para los españoles: 7 de cada diez sabe de su existencia, pero 
sólo 4 de cada 10 se interesa por seguirlo, eso sí, a través de la televisión.

2. Que el reflujo del debate le llega a 2 de cada diez españoles a través de la tele, a 1 por la radio y a otro por la prensa.

3. Que la última conclusión que les quedará del debate será el nombre del ganador. Al menos esto es lo que repetirán los medios a partir de algunas encuestas -tan eficaces como poco representativas- que dirán haber llevado a cabo. En cualquier caso, el punto de llegada no tiene nada que ver con el itinerario seguido: lo que empezó siendo un debate en el Parlamento acaba siendo un combate en los medios.

No obstante, conviene seguir insistiendo que el tratamiento no es igual en todos los casos. Mientras diarios como El País incluían hasta un gráfico que descomponía las partes de cada intervención, y por supuesto reproducían en sus páginas de Internet la totalidad de los discursos, en el caso de la televisión se ofrecieron imágenes fragmentarias, intentos de síntesis de los principales argumentos expuestos y de las posiciones mantenidas. Todo ello en un espacio de tiempo que osciló entre los 2 y los 5 minutos, según cadena.

Pero si dejamos una sesión tan especial como la que acabamos de tratar y nos vamos a una normal, nos encontraremos con que la atención televisiva se reduce a una mínima fracción de tiempo. Un proceso nada nuevo. En los Estados Unidos, hace 30 años el promedio de tiempo que los noticiarios de la televisión ofrecían a las palabras de un personaje político (por ejemplo, un candidato en una campaña presidencial) era de 42,3 segundos. A esos segmentos se les denomina sound-bites y dos décadas más tarde se habían reducido, en promedio, a 9,8 segundos ${ }^{14}$. ¿Qué argumentación sobre un hecho público relevante, o qué explicación puede ofrecérsele a los ciudadanos, en menos de diez segundos? Es evidente que esa rapidez de imágenes, ese ritmo en función del valor tiempo que define al modelo, es incompatible con la información en general y con la política en particular, ya que impide contextualizar, analizar, explicar y, sobre todo, reflexionar. Es decir, resulta imposible relacionar el acontecimiento del que se informa con la dinámica social e histórica que lo enmarca.

Más aún, los sound-bites que la televisión acostumbra recoger de una intervención política suelen ser aquellos en los que se muestra una frase jocosa, o una expresión ruda, pero no siempre aquella o aquellas que compendien las propuestas, o las tesis, del personaje político objeto de la información. Todo lo cual se aleja de los requisitos atribuidos a cualquier discurso político en una democracia deliberativa: 1) una exposición da los hechos que incorpore la explicación del escenario en el que discurran, con una mínima perspectiva temporal; 2)

14 SARTORI, Giovanni: "Videopoder", en Elementos de teoría política. Alianza, Madrid, 1992, p. 314. 
la crítica de los hechos, a partir de una evaluación de la acción de los actores presentes en dicho escenario: 3) conclusión y propuesta justificada en los valores que otorgan la propia identidad política ${ }^{15}$.

\section{Apuntando las consecuencias}

La televisión sigue siendo presentada hoy en día como la forma de conocimiento más accesible para todos los ciudadanos. Sin embargo, ya hemos demostrado cómo la televisión no repara en la profundidad reflexiva de los problemas, al tiempo que oculta una gran cantidad de información sin dar cuenta, explicar o reconocer que lo hacen por imperativos institucionales o restricciones de carácter estructural. Dicho en otros términos, con la televisión sucede lo que en los escaparates de los grandes almacenes: nos quedamos con lo que brilla y ni nos imaginamos lo que se oculta; nos quedamos con lo que exponen en el escaparate de sus papeles, diales o pantallas, pero apenas sabemos nada de su trastienda.

El problema es que una buena parte de esa lógica oculta del medio de comunicación, sobre todo del más influyente, la televisión, ha pasado a formar parte del mundo de la política. Se trata de un proceso que irrumpe con fuerza a finales de los setenta y que está dando lugar a una nueva forma de política tildada de diversas maneras: "Telecracia" (Sartori), democracia de las audiencias (Manin, 1998), de la opinión pública (Minc, 1995), "Telepolis" (Echevarria, 1994), "democracia mediática" (Muñoz-Alonso, 1999) o, simplemente, americanización de la política. El común denominador de todas ellas es afirmar la fusión entre la política y la televisión. Ya no se trata de la relación complementaria entre dos instituciones, tal y como veíamos anteriormente. Ahora, en este nuevo estadio, la política en general (con sus partidos, candidatos, elecciones...) ha asumido una buena parte de los principios retóricos y funcionales del mundo de la televisión. Hasta tal punto, que se anuncia el fin de los partidos políticos -en su concepción clásicasiendo sustituidos por un líder y gabinetes de expertos en comunicación.

La conclusión que se apunta es que nos encontramos ante un nuevo sistema político donde los partidos han perdido el papel de intermediarios de la representación popular en beneficio exclusivo de los medios; donde los valores democráticos se diluyen ante el fuerte escepticismo de los ciudadanos; donde la figura del político cada vez tiene menos prestigio.

En efecto, la política también ha quedado prisionera del esquema informativo del mundo televisivo. De aquí que la política seria, argumentada y explicativa no merezca la más mínima atención, mientras que la política escándalo, espectáculo o que provoque cualquier otra sensación, sea objeto de atención preferencial. El ejemplo más significado lo encontramos en el éxito del Partido Popular en su

15 SANPEDRO BLANCO, Víctor: Opinión pública y democracia deliberativa. Medios, sondeos y urnas. Istmo, Madrid, 2000, p. 71 
estrategia de acoso y derribo del PSOE. Como es bien sabido, las actuaciones de Aznar y otros líderes del partido se producían en función de la revelación sensacional que librarse cada mañana el diario El Mundo. El político dejó la iniciativa al periodista, sabiendo perfectamente que la denuncia realizada en un medio -especialmente prensa- siempre gozaría de más credibilidad que la realizada por cualquier político. El PSOE, como partido en el gobierno, contaba con la televisión pública, por boca de la cual intentaba contestar. La pugna mediática, trasunto de la política, no se cerró hasta las elecciones generales de 1996 en que triunfó Aznar.

El otro ejemplo de similares características sucede a raíz de la pérdida del poder por el PSOE. Se trata del proceso de enfrentamientos y divisiones que vivirá el partido por espacio de cuatro años y que los medios han convertido en noticia destacada, hasta tal punto que el fracaso electoral del PSOE en las generales del 2000 fue achacado en parte a esta imagen de desunión. Por el contrario, el funcionamiento homogéneo, vertical y sin fisuras del Partido Popular no sería objeto de atención mediática más que en determinadas ocasiones conmemorativas.

La conclusión de esta experiencia no ofrece dudas: si el partido político dividido o enfrentado es bocado apetitoso para los medios y acaba pagándolo electoralmente, la unidad y la disciplina deben de ser objetivos prioritarios. Y así sucede en los partidos mayoritarios actuales, aunque con notables diferencias. La consecuencia final es caer en la aberración de convertir al partido en un ejército organizado, donde la indisciplina se paga y la fidelidad se recompensa, donde las órdenes del jefe no se discuten y donde se combate al rival por cualquier medio de comunicación disponible las 24 horas del día. ¿No es sorprendente que el partido gobernante, depositario de la soberanía popular, tenga un funcionamiento autocrático?

Esta forma de hacer política nace en televisión, pero también acaba en ella en la medida que encuentra en su pantalla una fuente de legitimación social básica. Por el camino ha incorporado dos herramientas de investigación, los sondeos de opinión y el uso de la mercadotecnia, que determinan el rumbo a seguir modificando las reglas del juego electoral. La idea del programa político, del trabajo de los militantes y del apoyo de los sectores sociales que representan y defienden, va progresivamente perdiendo fuerza frente a la nueva escenografía que imponen los medios. El actor principal, el candidato, es a la vez el mensaje, quedando los argumentos o los programas relegados a una segunda instancia. La conducción de la campaña, ya electoral o ya de gobierno, pasa a estar dirigida por especialistas o profesionales de la comunicación. Por último, buena parte de la actuación del político se adecua a sondeos y encuestas que efectúan empresas demoscópicas ajenas al partido. Todo ello, porque el gran paradigma de la política en esta sociedad de la información es que si no sales, no existes. Las condiciones de éxito político, por tanto, pasan a depender inexorablemente de las condiciones de visibilidad mediática, y viceversa. 
A partir de este principio de actuación, la figura del político tradicional se ve reconvertida y adaptada a las exigencias del medio por donde se da a conocer. Irrumpe así la telegenia, versión mediática del antiguo carisma que se concreta en la capacidad comunicativa del líder político. Una capacidad estructurada y centrada en una serie de habilidades que van desde la facundia, el físico, la gestualidad, el vestuario, la escenografía... hasta la capacidad para entretener o divertiri ${ }^{16}$. En efecto, una mezcla de político/actor/vendedor, tal como pusiera de manifiesto la nominación y posterior éxito electoral de R. Reagan ${ }^{17}$. Pero también, una mezcla de showman, tal y como demostró Bill Clinton posteriormente. Su experiencia ha creado escuela. Recordemos que durante los meses previos a la contienda electoral propiamente dicha, los asesores del candidato demócrata a la presidencia constataron que los programas informativos de la televisión norteamericana le limitaban espacio a su candidato en beneficio de Bush. Encontraron entonces una estrategia sustitutiva. Clinton continuó haciendo su campaña presentándose en los programas de entretenimiento: Apareció en el Show de Arsenio Hall tocando el saxofón; pasó por el canal de música joven MTV; apareció en el Today-Show, en el Good-Morning Show y en CBS this Morning. Todo para conseguir tener audiencias masivas $\mathrm{y}$, tras el chiste o la gracia, poder vender su imagen y su candidatura.

Los políticos, como se observa, han adoptado una estrategia adaptativa prestándose a vehicular sus mensajes en este tipo de programas y, por tanto, asumiendo por completo los códigos de la espectacularidad y la banalidad. Todo en aras a convencer un número cada vez más importante de personas. De lo contrario, sus posibilidades de éxito se diluyen.

Igual sucede en los informativos. Si cada telediario, para ser más competitivo que el de enfrente, presenta la información en forma de imágenes sensacionales, trufada de todo tipo de anécdotas, simplificada argumentalmente para poder encajar en los breves segundos en que será expuesta, también los candidatos personalizan sus mensajes en una retórica de enfrentamiento dramático con los adversarios, simplifican sus propuestas en forma de titulares y programan sus exposiciones públicas en función de los horarios televisivos.

Esta forma de presentar la realidad que tiene la televisión, afecta cada vez más a las dimensiones cognitiva, afectiva y evaluativa de la cultura democrática. En primer lugar, a la televisión se le acusa de provocar un progresivo distanciamiento de los ciudadanos de la esfera política, al fomentar la idea de que los políticos constituyen un grupo especial de personajes dispuestos a hacer lo que sea con tal de tener poder. Los programas de humor que ridiculizan a los principales

16 BELANGER, A. J. : "La comunicación política o el juego del teatro y de las arenas", en Comunicación y Política, Gedisa, Barcelona, 1998, p. 137.

17 CONTRERAS, J. M. (1990): op. cit, p. 126 
líderes políticos y que tienen una amplia cobertura, alimentan la desconfianza, cuando no el cinismo, hacia el sistema en general y hacia los valores democráticos en particular. En definitiva, la televisión, como fuente principal de información de los ciudadanos, está generando una cultura antisistema al fomentar el abstencionismo político, tanto en la militancia partidista como en la práctica electoral, el individualismo más antisocial basado en la falsa idea de que gobierne quien gobierne los problemas sólo los soluciona uno, o la desmotivación para intervenir en los asuntos comunitarios.

Pero también se habla de otras consecuencias cognitivas de mayor calado: el triunfo de los sentimientos y la derrota de la mente, la imposición de la emoción frente a la reflexión. Y de nuevo por la lógica del medio, ya que la complejidad es antagónica con el objetivo prioritario de captar la atención. Por eso la noticia convencional se reduce a la retransmisión en directo de imágenes impactantes, que "hablan por sí mismas", pero que más allá de la conmoción que nos provocan apenas si descubrimos de qué hablan, el porqué sucede.

Asumimos sin cuestionarnos todo lo que aparezca, aunque lo que aparece no cuestione nada. El televidente ha pasado de ser un ente activo (que dirige sus propios pensamientos, sensaciones y conductas) a un ente reactivo (sin mediar volición o intencionalidad puede verse movido por una fuerza externa). El resultado es un consumo televisivo cada vez más acrítico, lo que a juicio de Marina podría provocar una renuncia a la elección ética y moral, que en última instancia "nos mantiene alertas, en vuelo, vivos, alejados de la facilidad, el automatismo, la inercia, la rutina de la vida animal". El peligro está en que es la "claudicación de la inteligencia racional lo que hace revivir en nosotros la querencia del rebaño o la jauría"18.

No extraña, por tanto, que hayan surgido voces que atribuyan a la televisión la responsabilidad de cambiar la naturaleza misma de la comunicación al haber empobrecido nuestra capacidad de entender. Se trata de la teoría apocalíptica que vaticina el fin del homo sapiens a manos de un homo videns. G. Sartori defiende tan sugestiva interpretación, acusando a la televisión de anular nuestra capacidad de abstracción y con ella toda nuestra capacidad de entender ${ }^{19}$. La base de esta afirmación es, precisamente, el mundo infantil y el grado de consumo de televisión que realizan: en Estados Unidos la media asciende a tres horas al día para los niños que no van aún a la escuela y a cinco horas diarias para los muchachos entre seis y doce años. También de que el niño es una esponja que registra y absorbe indiscriminadamente todo lo que ve (ya que no posee aún capacidad de discriminación y abstracción). Por el contrario, desde el otro punto de vista, el niño

18 MARINA, José Antonio: Ética para náufragos. Anagrama, Barcelona, 1995, p. 68.

19 SARTORI, Giovanni.: Homo Videns. La Sociedad teledirigida. Taurus Pensamiento Madrid, 1998, pp. 45 y ss. 
formado en la imagen se reduce a ser un hombre que no lee, que se instala en una cultura del no esfuerzo.

La televisión genera una cultura de la comodidad, del no esfuerzo, de apretar y consumir "lo que echen" con tal que no haga pensar. Esta tendencia recala luego en el mundo educativo, donde el ejercicio de aprender se pretende que sea equivalente a ver la televisión. Las clases son monótonas si no tienen un acompañamiento audiovisual; los libros son aburridos si sólo ofrecen texto; los profesores son un rollo sino trivializan los contenidos y cuentan muchas anécdotas. La televisión, como agente de socialización de los niños, no sólo le ha ganado la batalla a la familia, sino también a la escuela.

Esta transición desde la cultura del esfuerzo por aprender hacia la cultura de la comodidad por ver, no hace sino darle la razón al magnate alemán Axel Springer -editor de Bild Zeitung con más de 5 millones de ejemplares vendidos cada día-, que justificaba su éxito en una sola frase: "no hacer pensar a los alemanes". Y una televisión basada en la publicidad y en el imperativo económico de crear y mantener audiencias que proporcionen ingresos publicitarios, el no hacer pensar es principio de programación básico.

Pero no podemos resignarnos. Debemos pugnar por cambiar la tendencia, reivindicando una nueva política educativa que incorpore la pedagogía de la imagen como base para formar ciudadanos conscientes y críticos de lo que es y significa el mundo de la televisión. De igual manera, la enorme responsabilidad social de un medio tan influyente exige una mayor intervención pública y una menor confianza exclusiva en el mercado. Es urgente una nueva política que marque los límites a las televisiones privadas -incluidas las locales- y que devuelva a la pública la función de servicio público de primera necesidad. No sólo nuestro sistema de valores está en juego, también nuestro intelecto. 